\title{
Sternekoch Vincent Klink in der WLB
}

Am 8. September 2015 hat der Spitzenkoch Vincent Klink sein neues Buch „Ein Bauch spaziert durch Paris" in der WLB vorgestellt. Eine Premiere sowohl für die Bibliothek als auch für den Autor, denn es war die erste Buchvorstellung eines Sternekochs in der WLB. Eine Sensation auch für das Stuttgarter Publikum, denn das Buch ist erst ab dem 25. September im Buchhandel erhältlich bzw. wird erst am 21. September offiziell in Hamburg der Öffentlichkeit präsentiert - 250 Gäste kamen in den Genuss eines in vielerlei Hinsicht anregenden Abends mit einem gut gelaunten Vincent Klink und seiner spielfreudigen Jazzcombo "Brass on String Orchestra". Als Autor und Musiker nahm
Vincent Klink das Publikum humorvoll auf eine Reise durch Paris mit. Zwischen den einzelnen Lesungen spielte er auf seiner Basstrompete gemeinsam mit Eberhard Budziak (Posaune) und Boris Kischkat (Gitarre) Evergreens. Seine durchaus auch kritischen Beobachtungen und Einschätzungen enthielten eine Fülle von Geheimtipps für ParisLiebhaber. Ein vergnüglicher Abend mit viel Musik, Paris, guter Küche und entspannter Lebensart. Beim anschließenden Signieren verriet er, dass er auch dieses Buch zu großen Teilen in der WLB geschrieben hat, mit Kaffee und Laptop in der ehemaligen Cafeteria der Bibliothek.

Hannsjörg Kowark
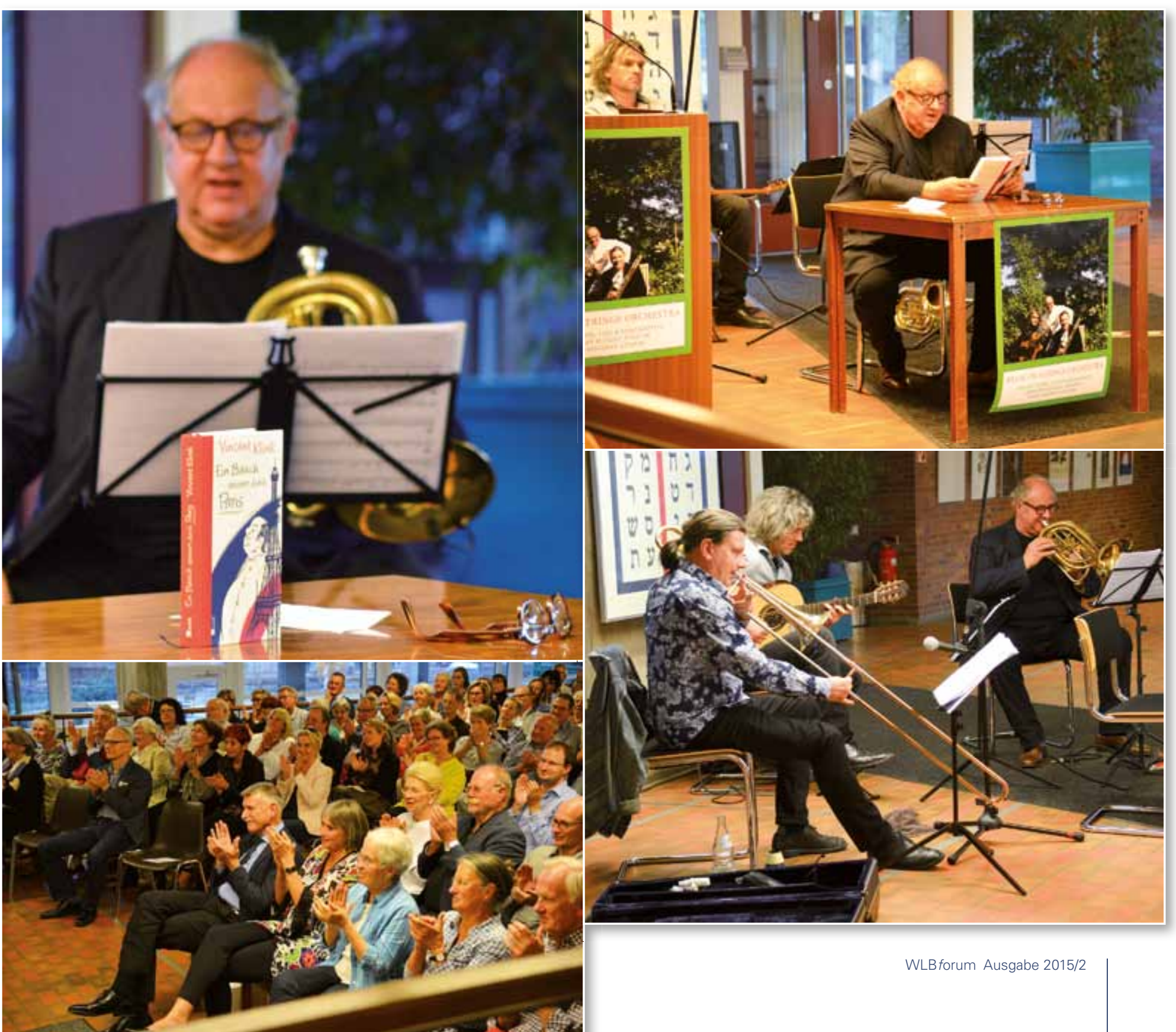